\title{
Original
}

\section{Protective effects of taxifolin on pazopanib-induced liver toxicity: an experimental rat model}

\author{
Baran AKAGUNDUZ ${ }^{1)}$, Muhammet OZER $^{2)}$, Fatih OZCICEK $^{3)}$, Ali Veysel KARA ${ }^{3)}$, Sahin LACIN $^{4}$, \\ Mustafa ÖZKARACA ${ }^{5)}$, Abdulkadir ÇOBAN ${ }^{6}$, Bahadır SULEYMAN ${ }^{7)}$, Renad MAMMADOV ${ }^{7)}$ \\ and Halis SULEYMAN ${ }^{7}$ \\ ${ }^{1)}$ Department of Medical Oncology, Erzincan Binali Yildirim University, Fatih Street \#124, 24030, Erzincan, Turkey \\ 2) Department of Internal Medicine, Capital Health Regional Medical Center, 750 Brunswich Avenue, 08638, Trenton, NJ, USA \\ 3) Department of Internal Medicine, Erzincan Binali Yildirim University, Fatih Street \#124, 24030, Erzincan, Turkey \\ 4) Department of Medical Oncology, Faculty of Medicine, Yeditepe University, 326 Atasehir, 34010, Istanbul, Turkey \\ ${ }^{5)}$ Department of Pathology, Faculty of Veterinary Medicine, Ataturk University, 12 Yakutiye Avenue, 25000, Erzurum, Turkey \\ ${ }^{6)}$ Department of Biochemistry, Faculty of Medicine, Erzincan Binali Yildirim University, Fatih Street \#124, 24030, Erzincan, \\ Turkey \\ 7) Department of Pharmacology, Faculty of Medicine, Erzincan Binali Yildirim University, Fatih Street \#124, 24030, Erzincan, \\ Turkey
}

\begin{abstract}
Pazopanib is a tyrosine kinase inhibitor that is generally used for the treatment of metastatic renal cell cancer and advanced soft tissue sarcoma. It can cause various degrees of hepatotoxicity. Our study aimed to investigate the effect of taxifolin on pazopanib-induced liver toxicity. A total of 18 rats were divided into three groups: the pazopanib (PP), pazopanib plus taxifolin (TPP), and control (C) group. Taxifolin was administered to the TPP $(n=6)$ group with a dose of $50 \mathrm{mg} / \mathrm{kg}$. Distilled water was orally admnistered to the $C(n=6)$ and $P P(n=6)$ groups as a solvent. Subsequently, pazopanib $200 \mathrm{mg} / \mathrm{kg}$ was administered to the TPP and PP groups via the stomach. This procedure was repeated once a day for four weeks. Then, all rats were sacrificed, and their livers were removed. Malondialdehyde (MDA), total glutathione (tGSH), total oxidant status (TOS), and total antioxidant status (TAS) levels were evaluated. MDA and TOS levels were higher in the PP group compared with the levels of the other parameters $(P<0.001)$. tGSH and TAS levels were lower in the PP group than in the TPP and C groups $(P<0.001)$, and the aspartate aminotransferase (AST), alanine aminotransferase (ALT), and lactate dehydrogenase $(\mathrm{LDH})$ levels were higher. Furthermore, liver tissue damage, including hemorrhage, hydropic degeneration, and necrosis was observed in the PP group. Administration of taxifolin before pazopanib significantly improved degenerative changes. Our study demonstrated that the administration of taxifolin is significantly effective in preventing pazopanib-induced hepatotoxicity in rats.
\end{abstract}

Key words: experimental models, liver toxicity, oxidative stress, pazopanib, taxifolin

\section{Introduction}

Pazopanib (Votrient), a tyrosine kinase inhibitor, was approved by the United States Food and Drug Administration (U.S. FDA) and the European Medicines Agency for renal cell carcinoma treatment [1]. It has also shown therapeutic efficacy in the treatment of non-adipocytic advanced soft tissue sarcoma [2, 3] and epithelial ovarian cancer [4]. Pazopanib is a multi-tyrosine kinase inhibitor targeting vascular endothelial growth factor receptors (VEGF) 1, 2, and 3; c-kit; and platelet-derived growth factor receptor (PDGF-R) [5]. Diarrhea, hypertension, heart toxicity, hemorrhagic and thromboembolic events, gastrointestinal perforation, neurological

(Received 17 July 2020 / Accepted 22 October 2020 / Published online in J-STAGE 26 November 2020)

Corresponding author: B. Akagunduz.e-mail: drbaran04@hotmail.com

This is an open-access article distributed under the terms of the Creative Commons Attribution Non-Commercial No Derivatives (by-nc-nd) License <http://creativecommons.org/licenses/by-nc-nd/4.0/>.

(C)2021 Japanese Association for Laboratory Animal Science 
disorders, acute pancreatitis, pneumothorax, and metabolic side effects have been observed during the use of pazopanib [6]. In clinical trials of pazopanib, hepatotoxicity manifested as an increase in serum transaminase (alanine aminotransferase, ALT; aspartate aminotransferase, AST) and bilirubin levels. Hepatotoxicity can be severe and fatal. Serum liver enzymes should be monitored before initiating pazopanib, and monitoring should be repeated at weeks $3,5,7$, and 9 ; at months 3 and 4; and as clinically indicated. Thereafter periodic monitoring should be performed. Due to this important side effect of pazopanib, it carries a boxed warning to alert patients and health-care professionals regarding the potential risk of liver damage [7]. In vitro screening of 31 small-molecule kinase inhibitors approved by the U.S. FDA revealed that pazopanib-associated liver toxicity involves mitochondria damage [8]. In recent studies, aldehyde derivatives and n-oxide metabolites of pazopanib have been demonstrated to trigger oxidative stress and increase free oxygen radicals, thereby causing hepatotoxicity [9-11]. Mingard et al. demonstrated that the mechanism of pazopanib-induced hepatotoxicity primarily can be due to increased oxidative stress in mitochondria [12]. In this context, information from the literature suggests that oxidative stress is one of the basic mechanisms of pazopanib-induced hepatotoxicity, and this can be eliminated with antioxidant therapy.

Flavonoids are one of the most frequently studied plant-based agents because of their wide distribution and potent antioxidant ability [13]. Dihydroflavonols a group of flavonoids, exhibit various biological activities, including reactive oxygen species (ROS) scavenging activity and metal-binding activity. Taxifolin (3,5,7,3', 4'-pentahydroxy-flavanone or 2,3-dihydroquercetin) is one of the dihydroflavonols with a minor component of silymarin, Pycnogenol, and Venoruton [14]. Taxifolin is present in French maritime pine bark, Douglas fir bark, and Siberian larch wood and also citrus fruits, grapes, olive oil, and onions in nature [15]. It can be easily extracted and used. Several studies have shown their role in the inhibition of free radical formation at key stages of apoptosis, especially in cerebral ischemia-reperfusion injury $[16,17]$. Taxifolin has also been found to have anticancer and neuroprotective effects [18-20]. In a recent study, Zhou et al. demonstrated that taxifolin showed high antioxidant capacity [21].

To the best of our knowledge, the protective effects of taxifolin against hepatotoxicity related to pazopanib have not been studied. Thus, we aimed to investigate if there are potential protective effects of taxifolin on pazopanibinduced hepatic injury in rats.

\section{Materials and Methods}

\section{Animals}

Eighteen male albino Wistar rats, each weighting between 277-290 g, supplied from the Ataturk University Medical Experiments Application and Research Center were used in the study. The rats were divided into three groups (six in each) and were kept in cages in a ventilated room with a 12-h light/12-h dark period, at constant temperature $\left(22^{\circ} \mathrm{C}\right)$, and free access to food and water. Animal experiments were performed in accordance with the National Institutes of Health Guidelines for the Use and Care of Laboratory Animals (NIH Publications No. 8023, revised 1978). The study was approved by the local animal ethics committee of Ataturk University, Erzurum, Turkey (Ethics Committee No.: 2020/46, dated April 16, 2020).

\section{Chemical agents}

The pazopanib used in the experiment was supplied by Novartis (Istanbul, Turkey), ketamin was supplied by Pfizer (Istanbul, Turkey), and taxifolin was supplied by Evalar Russia (Moscow, Russia).

\section{Experimental groups}

Experimental animals were divided into the following 3 groups: the control group (C), pazopanib alone (PP), and taxifolin + pazopanib (TPP) groups.

\section{Experimental procedure}

Taxifolin was orally administered to the TPP $(n=6)$ group with a dose of $50 \mathrm{mg} / \mathrm{kg}$ by gavage into the stomach. A total of $0.5 \mathrm{ml}$ distilled water was orally administered to the $\mathrm{C}(\mathrm{n}=6)$ and $\mathrm{PP}(\mathrm{n}=6)$ groups as a solvent. One hour after taxifolin or distilled water was given, pazopanib $200 \mathrm{mg} / \mathrm{kg}$ was administered to the TPP and PP groups via the stomach. We determined the dose of taxifolin and pazopanib based on previous studies. Taxifolin was found to be effective with a dose of $50 \mathrm{mg} / \mathrm{kg}$ in the treatment of cisplatin-induced oxidative damage [22]. Furthermore, previous studies showed that pazopanib is hepatotoxic at a dose of $150-300 \mathrm{mg} / \mathrm{kg}$ [9].

The above procedure was repeated once a day for four weeks. At the end of this period, all animals were sacrificed under anesthesia with high dose ketamine $(120 \mathrm{mg} /$ $\mathrm{kg})$ in combination with diazepam $(5 \mathrm{mg} / \mathrm{kg})$. Liver tissues of the rats were removed to measure the malondialdehyde (MDA), total glutathione ( $\mathrm{tGSH}$ ), total oxidant status (TOS), and total antioxidant status (TAS) levels. The liver tissues were examined histopathologically. In addition, ALT, AST, and lactate dehydrogenase (LDH) activities were measured in blood samples of animals. 
Blood samples were collected from the lateral tail vein of non-anesthetized rats. After treating the tail with warm water, the blood vessels were well dilated and suitable for manipulation.

\section{Biochemical analysis}

For biochemical analysis of liver tissues, homogenates were prepared from tissues, and 0.2 gr of the sample was taken from each tissue. Total glutathione and malondialdehyde levels in supernatants obtained from these homogenates were determined using appropriate methods based on the literature. The tissues were homogenized in ice-cold phosphate buffers $(50 \mathrm{mM}, \mathrm{pH} 7.4)$ that were appropriate for the variable to be measured. The tissue homogenates were centrifuged at 5,000 rpm for $20 \mathrm{~min}$ at $4^{\circ} \mathrm{C}$, and the supernatants were extracted to analyze tGSH and MDA. All spectrophotometric measurements were performed via a microplate reader (BioTek, Winoski, VT, USA).

\section{Malondialdehyde (MDA) analysis}

Quantitative analysis of MDA was based on the approach used by Ohkawa et al. related to spectrophotometric measurement of absorbance of the pink-colored complex formed by thiobarbituric acid (TBA) and MDA. The tissue-homogenate sample $(25 \mu \mathrm{l})$ was added to a solution containing $25 \mu \mathrm{l}$ of $80 \mathrm{~g} / \mathrm{l}$ sodium dodecyl sulfate and $1 \mathrm{ml}$ mixture solution $(200 \mathrm{~g} / \mathrm{l}$ acetic acid +1.5 $\mathrm{ml}$ of $8 \mathrm{~g} / 12$-thiobarbiturate) [23]. The mixture was incubated at $95^{\circ} \mathrm{C}$ for $1 \mathrm{~h}$. Upon cooling, $1 \mathrm{ml}$ of n-butanolpyridine (15:1) was added. The mixture was vortexed for $1 \mathrm{~min}$ and centrifuged for $10 \mathrm{~min}$ at $4,000 \mathrm{rpm}$. The absorbance of the supernatant was measured at $532 \mathrm{~nm}$. The standard curve was acquired by way of an approach using 1,1,3,3-tetramethoxypropane.

\section{Total glutathione analysis}

Total glutathione was analyzed using the method defined by Sedlak and Lindsay. DTNB (5,5'dithiobis [2nitrobenzoic acid]) disulfite is chromogenic medium, and DTNB is easily reduced by using sulfhydryl groups [24]. The yellow coloration in the course of reduction is measured via spectrophotometry at $412 \mathrm{~nm}$. For measurement, a cocktail solution ( $5.85 \mathrm{ml} 100 \mathrm{mM} \mathrm{Na}$-phosphate buffer, $2.8 \mathrm{ml} 1 \mathrm{mM}$ DTNB $3.75 \mathrm{ml} 1 \mathrm{mM}$ NADPH, and $80 \mu 1625 \mathrm{U} / 1$ glutathione reductase) was prepared. Before measurement, $0.1 \mathrm{ml}$ meta-phosphoric acid was added to $0.1 \mathrm{ml}$ tissue-homogenate and centrifuged for $2 \mathrm{~min}$ at 2,000 rpm for deproteinization. Then $0.15 \mathrm{ml}$ cocktail solution was added to $50 \mu \mathrm{l}$ of supernatant. The standard curve was obtained by using glutathione disulfide (GSSG).

\section{Measurement of TOS and TAS}

TOS and TAS levels of tissue homogenates were measured using a modern, automated method of determination and available kits (Rel Assay Diagnostics, Sehitkamil, Turkey), each produced by Erel et al. $[25,26]$. The TAS measurement method was based on the bleaching by antioxidants of the characteristic color of a more stable ABTS (2,2'-azino-bis (3-ethylbenzothiazoline6 -sulfonic acid)) radical cation and measurements at 660 $\mathrm{nm}$. The results were expressed in nmol hydrogen peroxide $\left(\mathrm{H}_{2} \mathrm{O}_{2}\right)$ equivalent/1. In the TOS method, the oxidants present in the sample oxidized the ferrous ion-odianisidine complex to ferric ion. Glycerol molecules, which were copiously present in the reaction medium, have improved the oxidation reaction. The ferric ion produced a colored complex with xylenol orange in an acidic medium. The intensity of the color, which could be spectrophotometrically measured at $530 \mathrm{~nm}$, was related to the total amount of oxidant molecules present in the sample. The results were expressed in $\mu \mathrm{mol}$ Trolox equivalent/l. The oxidative stress index (OSI) was used as the percentage ratio of TOS to TAS. OSI was calculated as TOS / TAS $\times 100$.

\section{ALT analysis}

Quantitative determination of serum ALT was performed by the spectrophotometric method with a Roche cobas 8000 autoanalyzer. The reaction between L-alanine and 2-oxoglutarate was catalyzed by 3,4 ALT. The pyruvate formed is reduced by $\mathrm{NADH}$ in a reaction catalyzed by L-lactate and $\mathrm{LDH}$, in which $\mathrm{NAD}^{+}$is formed. Pyridoxal phosphate acts as a coenzyme in the amino transfer reaction. It ensures complete enzyme activation. L-Alanine + 2-oxglutarate yields (ALT) pyruvate + Lglutamate, and Pyruvate $+\mathrm{NADH}+\mathrm{H}^{+}$yields $(\mathrm{LDH})$ L-lactate $+\mathrm{NAD}^{+}$. The rate of $\mathrm{NADH}$ oxidation rate is directly proportional to the catalytic ALT activity.

\section{AST analysis}

Quantitative determination of serum AST was performed by a spectrophotometric method with a Roche cobas 8000 autoanalyzer. AST catalyzes the transfer of an amino group between L-aspartate and 2-oxoglutarate to form 3,4 AST oxaloacetate and L-glutamate in the sample. Oxaloacetate then reacts with $\mathrm{NADH}$ in the presence of malate dehydrogenase (MDH) to form $\mathrm{NAD}^{+}$. Pyridoxal phosphate acts as a coenzyme in the amino transfer reaction. L-Aspartate +2 -oxglutarate yields (AST) oxaloacetate + L-glutamate, and oxaloacetate + $\mathrm{NADH}+\mathrm{H}^{+}$yields $(\mathrm{MDH}) \mathrm{L}-$ malate $+\mathrm{NAD}^{+}$. The rate of NADH oxidation is directly proportional to the catalytic AST activity. 


\section{LDH analysis}

Serum LDH quantitative determination was performed by the spectrophotometric method with a Roche cobas 8000 autoanalyzer. This is the standard method optimized according to Deutsche Gesellschaft für Klinische Chemie (DGKC). LDH catalyzes the reaction between pyruvate and NADH to form $\mathrm{NAD}^{+}$with L-lactate. Pyruvate $+\mathrm{NADH}+\mathrm{H}+$ yields $(\mathrm{LDH})$ L-lactate $+\mathrm{NAD}^{+}$. The initial rate of NADH oxidation is directly proportional to the catalytic LDH activity. The decrease in absorbance was determined by measuring at $340 \mathrm{~nm}$.

\section{Histopathological examination}

The liver tissues were placed into a $10 \%$ buffered formalin solution after necropsy of the rats. The samples were then subjected to routine follow-up and embedded in paraffin blocks. Five micrometer sections were taken from the block, placed onto slides, and subjected to histopathological examination under a light microscopy with hematoxylin-eosin staining. Evaluation of hemorrhage, hydropic degeneration, and necrosis was performed semiquantatively; 0 , none; 1 , mild; 2 , moderate; and 3 , severe.

\section{Statistical analysis}

Statistical analyses were conducted using IBM SPSS Statistics for Windows, version 19.0 Armonk, NY, USA. Descriptive statistics were calculated for each variable. The results were recorded as the mean \pm SD for continuous variables. The significance of the variations between the groups was determined using the method of one-way variance analysis (ANOVA), followed by the analysis by Turkey test. A $P$-value $<0.05$ was considered significant. In the histopathological examination, the differences between the groups were determined by Kruskal-Wallis test, which is one of the nonparametric tests, and groups that exhibited differences were determined by the Mann-Whitney U test. Between-group statistical differences for body weight changes of the rats were analyzed using the paired $t$-test.

\section{Results}

\section{Biochemical results}

The mean and median levels of parameters are shown in Table 1. Serum ALT, AST, and LDH levels were significantly higher in the PP group compared with the $\mathrm{C}$ and TPP groups $(P<0.001)$. ALT and AST levels were higher in the TPP group compared with the $\mathrm{C}$ group $(P<0.001 ; P<0,01)$; however, ALT and AST levels were significantly decreased in the TPP compared with the PP group. There was no significant difference between the $\mathrm{C}$ and TPP groups in terms of LDH levels $(P<0.001)$ (Fig. 1). MDA levels were significantly higher in the PP group compared with the $\mathrm{C}$ and TPP groups $(P<0.001)$. tGSH levels were significantly lower in the PP group compared with the $\mathrm{C}$ and TTP groups $(P<0.001)$. There was no statistically significant difference between the $\mathrm{C}$ and TPP groups in terms of MDA $(P<0.001)$. tGSH levels were lower in the TPP group compared with the $\mathrm{C}$ group $(P<0.001)$, but compared with the PP group, the tGSH levels were significantly increased in the TPP group (Fig. 2). TOS levels were significantly higher in the PP group compared with the C and TPP groups

Table 1. Biochemical results of the study

\begin{tabular}{|c|c|c|c|c|c|c|}
\hline & \multicolumn{2}{|c|}{$\mathrm{HG}(\mathrm{n}=6)$} & \multicolumn{2}{|c|}{$\mathrm{PP}(\mathrm{n}=6)$} & \multicolumn{2}{|c|}{ TPP $(n=6)$} \\
\hline & Mean \pm SD & $\begin{array}{l}\text { Medi an } \\
\text { (Min-Max) }\end{array}$ & Mean \pm SD & $\begin{array}{c}\text { Median } \\
\text { (Min-Max) }\end{array}$ & Mean \pm SD & $\begin{array}{l}\text { Median } \\
\text { (Min-Max) }\end{array}$ \\
\hline MDA ( $\mu \mathrm{mol} / \mathrm{g}$ protein $)$ & $5.12 \pm 0.18$ & $\begin{array}{c}5.13 \\
(4.79-5.31)\end{array}$ & $10.1 \pm 0.39^{*}$ & $\begin{array}{c}9.95 \\
(9.9-10.9)\end{array}$ & $5.45 \pm 0.33$ & $\begin{array}{c}5.35 \\
(5.22-6.11)\end{array}$ \\
\hline tGSH (nmol/g protein) & $7.28 \pm 0.15$ & $\begin{array}{c}7.3 \\
(7.1-7.42)\end{array}$ & $3.34 \pm 0.09 *$ & $\begin{array}{c}3.35 \\
(3.23-3.46)\end{array}$ & $6.83 \pm 0.06^{*}$ & $\begin{array}{c}6.79 \\
(6.76-6.92)\end{array}$ \\
\hline TOS (nmol $\mathrm{H}_{2} \mathrm{O}_{2} / \mathrm{mg}$ protein) & $8.25 \pm 0.42$ & $\begin{array}{c}8.3 \\
(7.7-8.8)\end{array}$ & $17.38 \pm 2.0^{*}$ & $\begin{array}{c}17.55 \\
(14.9-20.1)\end{array}$ & $8.71 \pm 0.35$ & $\begin{array}{c}8.72 \\
(8.11-9.1)\end{array}$ \\
\hline TAS ( $\mu$ mol Trolox equiv/mg protein) & $12.35 \pm 1.36$ & $\begin{array}{c}12.15 \\
(10.9-14.1)\end{array}$ & $5.35 \pm 0.19^{*}$ & $\begin{array}{c}5.37 \\
(5.11-5.61)\end{array}$ & $10.99 \pm 1.11$ & $\begin{array}{c}10.41 \\
(10.12-12.9)\end{array}$ \\
\hline $\operatorname{ALT}(\mathrm{U} / 1)$ & $27.8 \pm 2.6$ & $\begin{array}{c}28 \\
(24-31)\end{array}$ & $116.8 \pm 6.2^{*}$ & $\begin{array}{c}118.5 \\
(109-125)\end{array}$ & $37.8 \pm 3.2^{* *}$ & $\begin{array}{c}38.5 \\
(32-41)\end{array}$ \\
\hline $\operatorname{AST}(\mathrm{U} / 1)$ & $38.2 \pm 3$ & $\begin{array}{c}38.5 \\
(34-42)\end{array}$ & $245.5 \pm 6.6^{*}$ & $\begin{array}{c}245.5 \\
(237-255)\end{array}$ & $65.7 \pm 6.4^{*}$ & $\begin{array}{c}64.5 \\
(58-75)\end{array}$ \\
\hline LDH (U/l) & $135.3 \pm 6.9$ & $\begin{array}{c}137 \\
(122-141)\end{array}$ & $269.2 \pm 9.3^{*}$ & $\begin{array}{c}269 \\
(259-284)\end{array}$ & $144.2 \pm 9$ & $\begin{array}{c}145.5 \\
(130-155)\end{array}$ \\
\hline
\end{tabular}

$* * P<0.001$ compared with $\mathrm{C} . * P<0.01$ compared with C. C, control group; PP, pazopanib group; TPP, Taxifolin+pazopanib group. MDA, malondialdehyde; tGSH, total glutathione; TOS, total oxidant status; TAS, total antioxidant status; ALT, alanine aminotransferase; AST, aspartate aminotransferase; LDH, lactate dehydrogenase. 


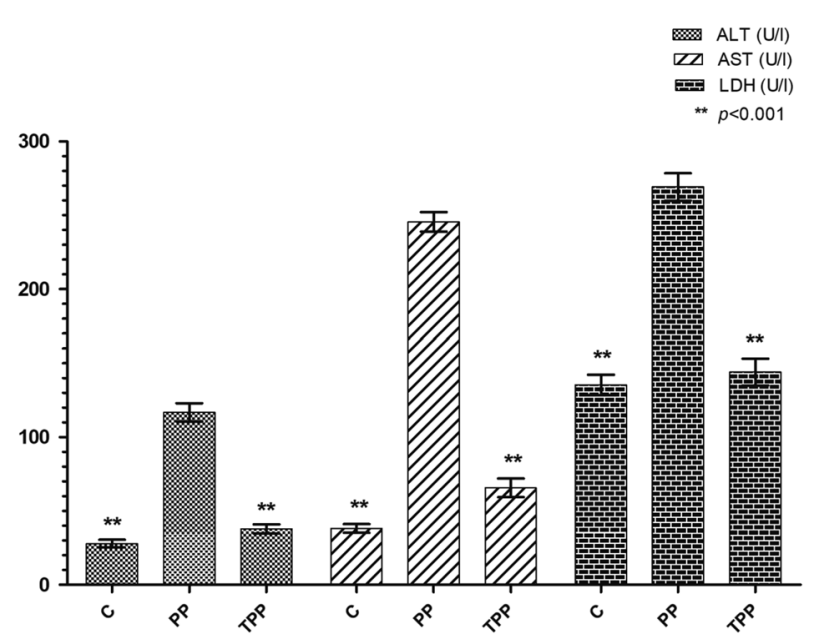

Fig. 1. The effects of taxifolin on AST, ALT, and LDH levels in blood samples of rats given pazopanib. Bars indicate the mean \pm SD. The healthy group is compared with the PP and TPP groups. AST, aspartat aminotransferase; ALT, alanine aminotransferase; $\mathrm{LDH}$, lactate dehydrogenase; $\mathrm{C}$, control group; TTP, taxifolin+pazopanip group; PP:, pazopanib group.

$(P<0.001)$. TAS levels were significantly lower in the PP group compared with the $\mathrm{C}$ and TPP groups. There was no significant difference between the $\mathrm{C}$ and TPP groups in terms of TAS and TOS levels $(P<0.001)$ (Fig. $3)$.

\section{Histopathological results}

At the time of the sacrificing the rats, we detected that body weight was increased from baseline in the $\mathrm{C}$ and TPP groups. However, body weight was decreased from baseline in the PP group (Table 2).

In the histopathological examination of the $\mathrm{C}$ group, we observed normal histology in rat liver tissues. In the PP group, we observed that hemorrhage and hydropic degeneration were severe, and in the TPP group, hemorrhage and hydropic degeneration were mild (Fig. 4). We also observed severe necrosis in hepatocytes in the PP group, whereas we observed mild necrosis in hepatocytes in the TPP group (Fig. 5). The histopathological findings were milder in the liver tissue of the TPP group. There was a significant difference between the groups (Table $3, P<0.05)$.

\section{Discussion}

Pazopanib is an oral agent that inhibits the tyrosine kinase inhibitors which is associated with vascular endothelial growth factor, platelet-derived growth factor, and Kit receptors. It is an effective treatment for advanced renal cell carcinoma (RCC) and soft tissue sarcoma [27-29]. Hepatotoxicity is a concern for its clini-

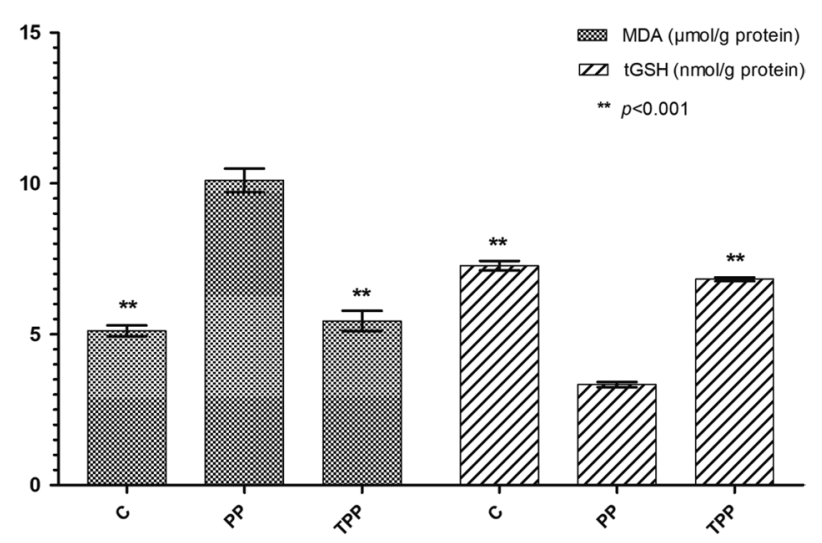

Fig. 2. The effects of taxifolin on MDA and tGSH levels in liver tissue of rats given pazopanib. Bars indicate the mean \pm SD. The healthy group is compared with the PP and TPP groups. MDA, malondialdehyde; $\mathrm{tGSH}$, total glutathione; $\mathrm{C}$, control group; TTP, taxifoli+pazopanip group; PP, pazopanib group.

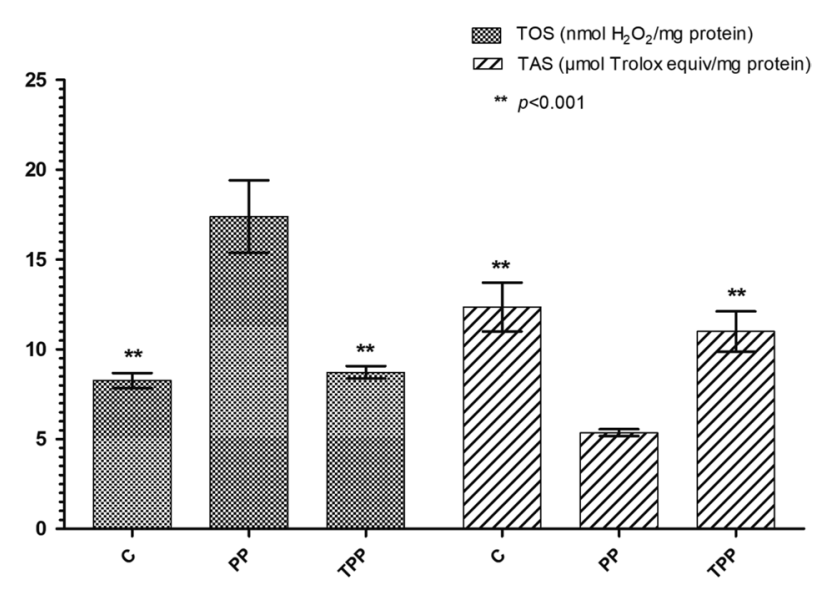

Fig. 3. The effects of taxifolin on TOS and TAS levels in liver tissue of rats given pazopanib. Bars indicate the mean \pm $\mathrm{SD}$. The healthy group is compared with the PP and TPP groups. TAS, total antioxidant status; TOS, total oxidant status; C, control group; TTP, taxifolin+pazopanip group; PP, pazopanib group.

Table 2. Body weight changes of the rats during the study

\begin{tabular}{lccc}
\hline Groups & $\begin{array}{c}\text { Body weight }(\mathrm{g}): \\
\text { Initial }\end{array}$ & $\begin{array}{c}\text { Body weight }(\mathrm{g}): \\
\text { End of experiment }\end{array}$ & $P$ value \\
\hline C & $282.3 \pm 5.7$ & $292.5 \pm 4$ & 0.003 \\
PP & $283.3 \pm 4.2$ & $274.2 \pm 3.3$ & 0.003 \\
TPP & $283.8 \pm 5.6$ & $288.8 \pm 3.4$ & 0.021 \\
\hline
\end{tabular}

cal application. Pazopanib-induced ALT and AST elevations are commonly observed in patients and range from 46 to $60 \%$ for all toxicity grades, from 8 to $15 \%$ for grade 3 toxicity, and from $<1 \%$ to $2 \%$ for grade 4 toxicity [7]. A meta-analysis of clinical trials of pazopanib confirmed a $42 \%$ incidence of all-grade ALT increase and $8.2 \%$ incidence of high-grade ALT increase [30]. Pazopanib-induced hepatotoxicity has been associ- 

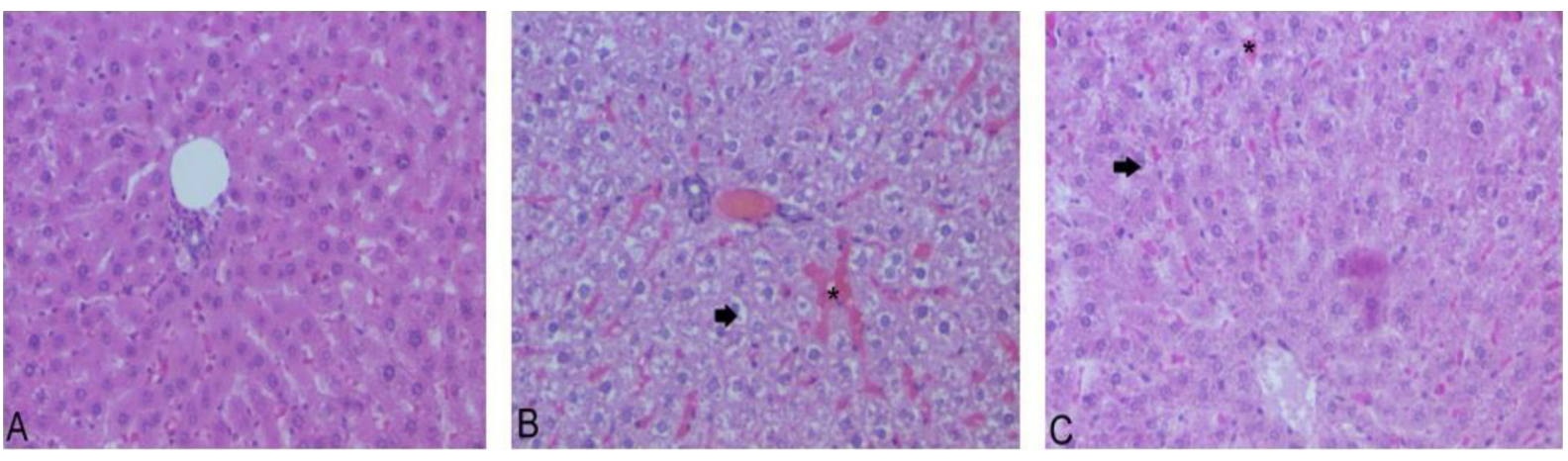

Fig. 4. A. The healthy group shows a normal histological appearance. B. The pazopanib group shows severe hydropic degeneration (arrow) and hemorrhage $(*)$. C. The taxifolin+pazopanib group shows mild hydropic degeneration (arrow) and hemmorrhage $(*)$.
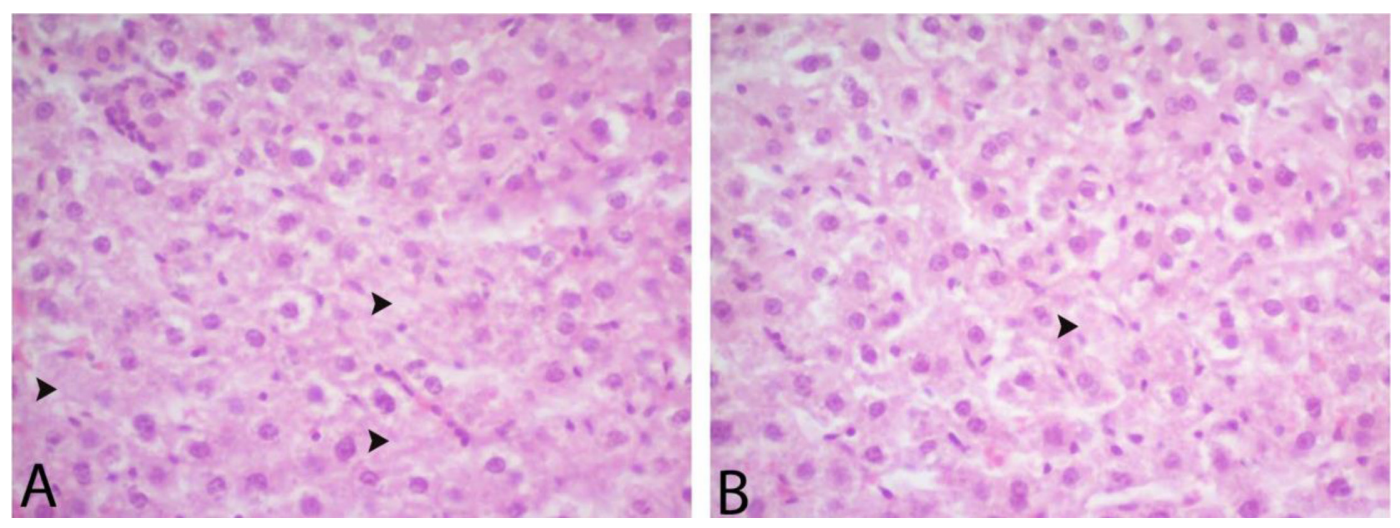

Fig. 5. A. The pazopanib group shows severe necrosis (arrows) in hepatocytes. B. The taxifolin+pazopanib group shows mild necrosis (arrows) in hepatocytes.

Table 3. Histopathological results of the study

\begin{tabular}{lccc}
\hline Groups & Hemorrhage & Hydropic degeneration & Necrosis \\
\hline C & $0.16 \pm 0.51^{*}$ & $0.33 \pm 0.51^{*}$ & $0.33 \pm 0.40^{*}$ \\
PP & $2.83 \pm 0.40^{* *}$ & $2.83 \pm 0.40^{* *}$ & $2.16 \pm 0.40^{* *}$ \\
TPP & $1.33 \pm 0.51^{* * *}$ & $1.16 \pm 0.40^{* * *}$ & $1.16 \pm 0.51^{* * *}$ \\
\hline
\end{tabular}

Asterisks $(*, * *, * * *)$ indicate differences between groups $(P<0.05)$. C, control group; PP, pazopanib group; TPP, taxifolin+pazopanib group.

ated with the HFE (hemochromatosis gene) mutation on chromosome 6 [31], but the exact mechanisms of pazopanib-induced liver injury remain unclear. Cetin et al. demonstrated the pazopanib-induced hepatotoxicity biochemically and histopathologically in an experimental rat model [32]. Wang et al. demonstrated that pazopanib triggered oxidative stress, increased free oxygen radicals, and caused hepatotoxicity [9]. It has also been reported that pazopanib-induced hepatotoxicity can be due to increased oxidative stress in mitochondria [12]. These findings indicate that oxidative stress can be an important mechanism of pazopanib-induced hepatotoxicity.

Flavonoids are one of the main groups of plant phenolic antioxidants and have high chelating properties
[33]. They are widely found in leaves and flowers of plants and also abundantly found in foods and beverages made from plants [34]. Taxifolin (3,5,7,3,4-pentahydroxy flavanone or dihydroquercetin) is a flavanolol, which is a subclass of flavonoids, and it is mainly found in citrus fruits, onions, olive oil, etc. [35]. Topal et al. showed that taxifolin had significant antioxidant, radical scavenging, and chelating activity. They suggested that it can be used in the food and pharmaceutical industry to decrease the formation of toxic oxidation products [36]. Kara and colleagues showed that taxifolin has protective effects that reduce cisplatin-induced oxidative renal injury [37].

In this study, we investigated the protective effect of taxifolin on pazopanib-induced liver toxicity in rats. Our 
biochemical results indicate that pazopanib increased the levels of MDA and TOS, which are oxidant parameters, and decreased the levels of tGSH and TAS, which are antioxidant parameters, in liver tissues of rats. Similarly, serum AST, ALT, and LDH levels were significantly higher in the PP group as compared with the TPP group. Pazopanib caused hemorrhage, hydropic degeneration, and necrosis in rat liver tissues. Histopathological examinations revealed reduced pazopanib-induced liver damage in the TPP group. We observed that taxifolin at a dose of $50 \mathrm{mg} / \mathrm{kg}$ has histopathological and biochemical protective effects against pazopanib-induced oxidative liver toxicity. Our results showed that pazopanib changed the oxidant-antioxidant balance in favor of oxidants in the liver tissue of rats and subsequently caused liver tissue damage and increased serum AST, ALT, and LDH levels. These biochemical results of this study were fully consistent with the histopathological results. Taxifolin inhibited the oxidant effects of pazopanib.

\section{Conclusion}

In conclusion, we have demonstrated fort he first time in the literature that taxifolin can prevent pazopanibinduced liver toxicity in rat models. The promising results of this study indicate that further studies are needed to test this agent in other animal models and in humans.

\section{References}

1. Pal SK, Hossain DMS, Zhang Q, Frankel PH, Jones JO, Carmichael $\mathrm{C}$, et al. Pazopanib as third line therapy for metastatic renal cell carcinoma: clinical efficacy and temporal analysis of cytokine profile. J Urol. 2015; 193: 1114-1121. [Medline] [CrossRef]

2. Endo M, Nielsen TO. Pazopanib for metastatic soft-tissue sarcoma. Lancet. 2012; 380: 801, author reply 801. [Medline] [CrossRef]

3. Karch A, Koch A, Grünwald V. A phase II trial comparing pazopanib with doxorubicin as first-line treatment in elderly patients with metastatic or advanced soft tissue sarcoma (EPAZ): study protocol for a randomized controlled trial. Trials. 2016; 17: 312. [Medline] [CrossRef]

4. Dinkic C, Eichbaum M, Schmidt M, Grischke EM, Gebauer G, Fricke HC, et al. Pazopanib (GW786034) and cyclophosphamide in patients with platinum-resistant, recurrent, pretreated ovarian cancer - Results of the PACOVAR-trial. Gynecol Oncol. 2017; 146: 279-284. [Medline] [CrossRef]

5. Sleijfer S, Ray-Coquard I, Papai Z, Le Cesne A, Scurr M, Schöffski P, et al. Pazopanib, a multikinase angiogenesis inhibitor, in patients with relapsed or refractory advanced soft tissue sarcoma: a phase II study from the European organisation for research and treatment of cancer-soft tissue and bone sarcoma group (EORTC study 62043). J Clin Oncol. 2009; 27 : 3126-3132. [Medline] [CrossRef]

6. Pick AM, Nystrom KK. Pazopanib for the treatment of metastatic renal cell carcinoma. Clin Ther. 2012; 34: 511-520. [Medline] [CrossRef]
7. Administration USF and D. Pazopanib (Votrient) prescribing information. 2010.

8. Zhang J, Salminen A, Yang X, Luo Y, Wu Q, White M, et al. Effects of 31 FDA approved small-molecule kinase inhibitors on isolated rat liver mitochondria. Arch Toxicol. 2017; 91: 2921-2938. [Medline] [CrossRef]

9. Wang YK, Yang XN, Liang WQ, Xiao Y, Zhao Q, Xiao XR, et al. A metabolomic perspective of pazopanib-induced acute hepatotoxicity in mice. Xenobiotica. 2019; 49: 655-670. [Medline] [CrossRef]

10. Yang M, Ruan J, Gao H, Li N, Ma J, Xue J, et al. First evidence of pyrrolizidine alkaloid N-oxide-induced hepatic sinusoidal obstruction syndrome in humans. Arch Toxicol. 2017; 91: 3913-3925. [Medline] [CrossRef]

11. Choudhury Y, Toh YC, Xing J, Qu Y, Poh J, Li H, et al. Patient-specific hepatocyte-like cells derived from induced pluripotent stem cells model pazopanib-mediated hepatotoxicity. Sci Rep. 2017; 7: 41238. [Medline] [CrossRef]

12. Mingard C, Paech F, Bouitbir J, Krähenbühl S. Mechanisms of toxicity associated with six tyrosine kinase inhibitors in human hepatocyte cell lines. J Appl Toxicol. 2018; 38: 418-431. [Medline] [CrossRef]

13. Kumar S, Pandey AK. 2013. Chemistry and biological activities of flavonoids: an overview. ScientificWorldJournal 2013: 162750. [Medline] [CrossRef]

14. Mülek M, Seefried L, Genest F, Högger P. Distribution of constituents and metabolites of maritime pine bark extract (Pycnogenol ${ }^{\circledR}$ ) into serum, blood cells, and synovial fluid of patients with severe osteoarthritis: a randomized controlled trial. Nutrients. 2017; 9: 443. [Medline] [CrossRef]

15. Slimestad R, Fossen T, Vågen IM. Onions: a source of unique dietary flavonoids. J Agric Food Chem. 2007; 55: 1006710080. [Medline] [CrossRef]

16. Chirino YI, Pedraza-Chaverri J. Role of oxidative and nitrosative stress in cisplatin-induced nephrotoxicity. Exp Toxicol Pathol. 2009; 61: 223-242. [Medline] [CrossRef]

17. Maksimovich NY, Dremza IK, Troian EI, Maksimovich YN, Borodinskii AN. [The correcting effects of dihydroquercetin in cerebral ischemia-reperfusion injury]. Biomed Khim. 2014; 60: 643-650. [Medline] [CrossRef]

18. Zhang ZR, Al Zaharna M, Wong MMK, Chiu SK, Cheung HY. Taxifolin enhances andrographolide-induced mitotic arrest and apoptosis in human prostate cancer cells via spindle assembly checkpoint activation. PLoS One. 2013; 8: e54577. [Medline] [CrossRef]

19. Manigandan K, Manimaran D, Jayaraj RL, Elangovan N, Dhivya V, Kaphle A. Taxifolin curbs NF- $\kappa$ B-mediated Wnt/ $\beta$ catenin signaling via up-regulating $\mathrm{Nrf} 2$ pathway in experimental colon carcinogenesis. Biochimie. 2015; 119: 103-112. [Medline] [CrossRef]

20. Dok-Go H, Lee KH, Kim HJ, Lee EH, Lee J, Song YS, et al. Neuroprotective effects of antioxidative flavonoids, quercetin, $(+)$-dihydroquercetin and quercetin 3-methyl ether, isolated from Opuntia ficus-indica var. saboten. Brain Res. 2003; 965 : 130-136. [Medline] [CrossRef]

21. Zhou S, Shao Y, Fu J, Xiang L, Zheng Y, Li W. Characterization and Quantification of Taxifolin Related Flavonoids in Larix olgensis Henry Var. koreana Nakai Extract Analysis and its Antioxidant Activity Assay. Int J Pharmacol. 2018; 14 : 534-545. [CrossRef]

22. Erhan E, Bayram R, Cimen FK, Altuner D, Seckin E, Kurt $\mathrm{N}$, et al. The effect of taxifolin on cisplatin induced oxidative cochlear damage in rats: biochemical and histopathological examination. Acta Pol Pharm Res. 2019; 76: 895-900.

23. Ohkawa H, Ohishi N, Yagi K. Assay for lipid peroxides in animal tissues by thiobarbituric acid reaction. Anal Biochem. 1979; 95: 351-358. [Medline] [CrossRef]

24. Sedlak J, Lindsay RH. Estimation of total, protein-bound, and nonprotein sulfhydryl groups in tissue with Ellman's reagent. Anal Biochem. 1968; 25: 192-205. [Medline] [CrossRef] 
25. Erel O. A new automated colorimetric method for measuring total oxidant status. Clin Biochem. 2005; 38: 1103-1111. [Medline] [CrossRef]

26. Erel O. A novel automated method to measure total antioxidant response against potent free radical reactions. Clin Biochem. 2004; 37: 112-119. [Medline] [CrossRef]

27. van der Graaf WTA, Blay JY, Chawla SP, Kim DW, BuiNguyen B, Casali PG, et al. EORTC Soft Tissue and Bone Sarcoma Group PALETTE study group. Pazopanib for metastatic soft-tissue sarcoma (PALETTE): a randomised, doubleblind, placebo-controlled phase 3 trial. Lancet. 2012; 379: 1879-1886. [Medline] [CrossRef]

28. Motzer RJ, Hutson TE, Cella D, Reeves J, Hawkins R, Guo J, et al. Pazopanib versus sunitinib in metastatic renal-cell carcinoma. N Engl J Med. 2013; 369: 722-731. [Medline] [CrossRef]

29. Sternberg CN, Davis ID, Mardiak J, Szczylik C, Lee E, Wagstaff J, et al. Pazopanib in locally advanced or metastatic renal cell carcinoma: results of a randomized phase III trial. J Clin Oncol. 2010; 28: 1061-1068. [Medline] [CrossRef]

30. Kapadia S, Hapani S, Wu S. Risk of high-grade liver toxicity with pazopanib in patients with cancer: A meta-analysis. J Clin Oncol. 2011; 29: 4595. [CrossRef]
31. Xu CF, Reck BH, Goodman VL, Xue Z, Huang L, Barnes MR, et al. Association of the hemochromatosis gene with pazopanib-induced transaminase elevation in renal cell carcinoma. J Hepatol. 2011; 54: 1237-1243. [Medline] [CrossRef]

32. Cetin B, Y1lmaz GE, Armagan B, Afsar B, Demirci U, Gulbahar O, et al. Pazopanib-Induced Hepatotoxicity in an Experimental Rat Model. Chemotherapy. 2018; 63: 39-45. [Medline] [CrossRef]

33. Rice-Evans CA, Miller NJ, Paganga G. Structure-antioxidant activity relationships of flavonoids and phenolic acids. Free Radic Biol Med. 1996; 20: 933-956. [Medline] [CrossRef]

34. Panche AN, Diwan AD, Chandra SR. Flavonoids: an overview. J Nutr Sci. 2016; 5: e47. [Medline] [CrossRef]

35. Weidmann AE. Dihydroquercetin: More than just an impurity? Eur J Pharmacol. 2012; 684: 19-26. [Medline] [CrossRef]

36. Topal F, Nar M, Gocer H, Kalin P, Kocyigit UM, Gülçin I, et al. Antioxidant activity of taxifolin: an activity-structure relationship. J Enzyme Inhib Med Chem. 2016; 31: 674-683. [Medline] [CrossRef]

37. Kara AV, Aldemir MN, Ozcicek F, Mammadov R, Yazıcı $\mathrm{GN}$, Sunar M, et al. Protective effect of taxifolin on cisplatininduced nephrotoxicity in rats. Anal Quant Cytopathol Histpathol. 2019; 41: 47-54. 